\title{
INTERKULTURALNA EFIKASNOST I PREFERENCIJE GLAZBI SVIJETA U KONTEKSTU VISOKOŠKOLSKOG OBRAZOVANJA
}

\author{
Snježana Dobrota ${ }^{1}$, Mirna Vukić ${ }^{2}$ \\ ${ }^{1}$ Filozofski fakultet, Sveučilište u Splitu, Hrvatska \\ ${ }^{2}$ Split, Hrvatska \\ dobrota@ffst.hr; mvukic@ffst.hr
}

Primljeno: 3. 12. 2020.

U radu je istražen utjecaj završenog srednjoškolskog obrazovanja $i$ dobi/godine studije na interkulturalnu efikasnost studenata $i$ njihove preferencije glazbi svijeta, zatim povezanost između interkulturalne efikasnosti $i$ preferencija glazbi svijeta te utjecaj poznatosti na preferencije glazbenih ulomaka. Istraživanje je provedeno na uzorku studenata različitih fakulteta Sveučilišta u Splitu i Sveučilišta u Zagrebu, pomoću upitnika sastavljenog od tri dijela: Upitnik općih podataka, Upitnik interkulturalne efikasnosti (The Intercultural Effectiveness Scale) te Upitnik za ispitivanje glazbenih preferencija. Rezultati ne potvrđuju utjecaj vrste završene srednje škole ni dobi/ godine studija na razinu interkulturalne efikasnosti studenata, niti na njihove preferencije glazbi svijeta. Potvrdeno je postojanje povezanosti između razine interkulturalne efikasnosti i preferencija glazbi svijeta te između poznavanja glazbe i preferencija glazbenih ulomaka. Dobiveni rezultati imaju značajne glazbeno-pedagoške implikacije, posebno u kontekstu visokoškolskog obrazovanja.

Ključne riječi: glazbena pedagogija, interkulturalna efikasnost, preferencije glazbi svijeta, visokoškolsko obrazovanje 


\section{Uvod'}

Kao rezultat sveprisutnih trendova globalizacije, sve veće sofisticiranosti komunikacijskih tehnologija i internacionalizacije obrazovanja u suvremenom društvu, povećava se važnost proučavanja fenomena interkulturalne komunikacijske kompetencije. Interkulturalna komunikacijska kompetencija predstavlja sposobnost pojedinca za ostvarivanje komunikacijskih ciljeva, koristeći pritom efikasne i odgovarajuće komunikacijske metode posredovanja između različitih identiteta koji su prisutni u kulturno heterogenim sredinama (Portalla i Chen, 2010).

Navedena kompetencija obuhvaća tri dimenzije i to interkulturalnu svijest, interkulturalnu osjetljivost i interkulturalnu efikasnost (Chen i Starosta, 1996). Dok interkulturalna svijest predstavlja kognitivni proces pomoću kojega osoba dolazi do spoznaje o svojoj kulturi i o nepoznatim kulturama, interkulturalna osjetljivost odnosi se na afektivni aspekt koji predstavlja sposobnost pojedinca da razlikuje, procjenjuje i respektira ponašanja, percepcije i osjećaje ljudi iz različitih kulturnih sredina (Chen i Starosta, 1997). I, konačno, interkulturalna efikasnost je bihejvioralni aspekt interkulturalne komunikacijske kompetencije i označava sposobnost ostvarivanja komunikacijskih ciljeva u interkulturalnim interakcijama.

Cushner i Brislin (1996) smatraju da, kako bismo zadovoljili potrebe i ciljeve komunikacije $u$ heterogenim društvima, moramo ojačati svoju interkulturalnu svijest, osjetljivost i kompetencije. Prema Hammeru, Gudykunstu i Wisemanu (1978), interkulturalnu efikasnost sačinjavaju tri sposobnosti i to: sposobnost savladavanja psihološkog stresa, sposobnost efikasne komunikacije i sposobnost ostvarivanja interpersonalnih odnosa.

Slijedom rečenog, osoba koja posjeduje visoku razinu interkulturalne efikasnosti sposobna je izabrati verbalna i neverbalna ponašanja te komunikacijske stilove koji su najprikladniji tijekom određene interkulturalne komunikacije. Takva osoba pokazuje poštivanje prema

${ }^{1} \mathrm{Rad}$ pod naslovom Interkulturalna efikasnost i preferencije glazbi svijeta u kontekstu visokoškolskog obrazovanja diplomska je radnja Mirne Vukić, obranjena 2021. godine na Filozofskom fakultetu Sveučilišta u Splitu, na Odsjeku za učiteljski studij, pod mentorstvom dr. sc. Snježane Dobrota. 
drugom i drugačijem te se ponaša u skladu s pravilima i vrijednostima određene kulture (Chen i Starosta, 1996).

Problematikom interkulturalnog obrazovanja u kontekstu razvijanja interkulturalnih kompetencija učenika i studenata bavio se veliki broj autora (Fylkesnes, 2018; Hutchins i Goldstein-Hode, 2019; Kim, Wee i Lee, 2016; King, Perez i Shim, 2013). Rezultati generalno potvrđuju značajnu ulogu interkulturalnog obrazovanja u smanjivanju predrasuda i razvijanju interkulturalne osjetljivosti, interkulturalnih stavova $i$ interkulturalne efikasnosti učenika i studenata.

Nastava glazbe na svim razinama obrazovanja, kako u Hrvatskoj tako i u svijetu, uglavnom počiva na zapadnoj umjetničkoj tradiciji koju glazbeni pedagozi prihvaćaju kao glazbenu univerzaliju (Dobrota, 2012). Tako se nastava glazbe u hrvatskim srednjim školama uglavnom realizira prema dijakronijskom modelu, u kojemu program slijedi kronološki tijek razvoja glazbe (Rojko, 2001, 4). Rojko (2001) ističe brojne nedostatke toga modela pa tako navodi da nije u suglasju s interesima učenika te da je pretjerano opširan i opterećen verbalizmom. Za razliku od dijakronijskog modela, u sinkronijskom modelu u prvom planu je glazba i njeni pojavni oblici, pa Rojko smatra da je takav model bolji, moderniji i zanimljiviji od dijakronijskog modela (Rojko, 2001). Rezultati brojnih istraživanja potvrđuju da glazba često nije omiljeni predmet među učeničkom populacijom, što se posebno odnosi na gimnazijalce (Bray, 2000). Ross (1995) uočava da je glazba jedan od najnepopularnijih predmeta u srednjoj školi, prije svega zato što učitelji nisu voljni prilagoditi se novim izazovima.

Jedan spektar takvih izazova odnosi se na promicanje interkulturalnog glazbenog obrazovanja u vrtićima, školama i visokoškolskim institucijama. Rezultati brojnih istraživanja (Campbell, 2003; Dobrota, 2016; Fung, 1994; Kang, 2016; Klopper, 2010) potvrđuju značajan doprinos interkulturalnog glazbenog obrazovanja upoznavanju različitih kultura, prevladavanju različitih predrasuda i razvijanju tolerancije i razumijevanja. Budući da se mali broj istraživanja bavio pitanjem odnosa preferencija glazbi svijeta i interkulturalne efikasnosti, u ovom ćemo istraživanju ispitati navedenu problematiku na studentskoj populaciji. 


\section{Cilj, problem i hipoteze istraživanja}

Cilj istraživanja bio je istražiti razlikuju li se interkulturalna efikasnost studenata i njihove preferencije glazbi svijeta s obzirom na završeno srednjoškolsko obrazovanje i dob/godinu studija, zatim povezanost između interkulturalne efikasnosti i preferencija glazbi svijeta te utjecaj poznatosti na preferencije glazbenih ulomaka.

U skladu s formuliranim ciljem, postavljeni su sljedeći problemi istraživanja:

1. Ispitati razlikuje li se razina interkulturalne efikasnosti studenata $\mathrm{s}$ obzirom na vrstu završene srednje škole i dob/godinu studija.

2. Ispitati razlikuju li se preferencije glazbi svijeta studenata s obzirom na vrstu završene srednje škole i dob/godinu studija.

3. Ispitati postoji li povezanost između razine interkulturalne efikasnosti i preferencija glazbi svijeta.

4. Ispitati postoji li povezanost između poznavanja i preferencija glazbenih ulomaka.

Na temelju definiranog cilja i problema istraživanja postavljene su sljedeće hipoteze:

H1: Studenti koji su završili gimnaziju i studenti viših godina studija, u odnosu na studente iz strukovnih škola i studente nižih godina studija, imaju višu razinu interkulturalne efikasnosti.

H2: Studenti koji su završili gimnaziju i studenti viših godina studija, u odnosu na studente iz strukovnih škola i studente nižih godina studija, pokazuju veće preferencije glazbi svijeta.

H3: Studenti koji imaju višu razinu interkulturalne efikasnosti, pokazuju i veće preferencije glazbi svijeta.

H4: Studenti pokazuju veće preferencije poznatih, u odnosu na nepoznate glazbene ulomke.

\subsection{Metoda}

\subsubsection{Sudionici}

Ispitivanje je provedeno putem online ankete na uzorku od 141 sudionika, studenata prve, druge, treće, četvrte i pete godine različitih fakulteta Sveučilišta u Splitu i Sveučilišta u Zagrebu. Studenti prve, 
druge i treće godine sačinjavaju jednu skupinu $(\mathrm{N}=54)$, a studenti četvrte i pete godine drugu skupinu ( $\mathrm{N}=87)$ (Tablica 1).

Tablica 1. Struktura uzorka $(\mathrm{N}=141)$

\begin{tabular}{|c|c|c|c|}
\hline Spol & $\mathbf{N}$ & Dob & $\mathbf{N}$ \\
\hline $\mathrm{M}$ & 19 & 1., 2., 3. godina studija & 54 \\
\hline$\check{Z}$ & 122 & 4. i 5. godina studija & 87 \\
\hline Ukupno & \multicolumn{3}{|c}{141} \\
\hline
\end{tabular}

\subsubsection{Instrument i postupak ispitivanja}

Za potrebe istraživanja konstruiran je upitnik. U prvom dijelu, Upitniku općih podataka, prikupljeni su sociodemografski podatci o sudionicima (spol, završena srednja škola, fakultet i studijska grupa, godina studija). Drugi dio, Upitnik interkulturalne efikasnosti (The Intercultural Effectiveness Scale) (Portalla i Chen, 2010), sadrži dvadeset tvrdnji koje ispituju različite aspekte interkulturalne efikasnosti i to: sposobnost prenošenja poruke, upravljanje interakcijom, bihejvioralna fleksibilnost, upravljanje identitetom, opuštenost u interakciji te poštovanje prema sugovorniku. Uz svaku tvrdnju priložena je skala procjene Likertova tipa od 1 do 5 (1=uopće se ne slažem; $5=$ u potpunosti se slažem). Provedenom eksploratornom faktorskom analizom dobiveni su faktori koji se značajno razlikuju od izvornika, stoga se u daljnjoj obradi koristio ukupni rezultat skale. Psihometrijske značajke skale prikazane su u Tablici 2.

Tablica 2. Psihometrijske značajke Skale interkulturalne efikasnosti

\begin{tabular}{|c|l|}
\hline $\begin{array}{c}\text { Broj } \\
\text { tvrdnje }\end{array}$ & \multicolumn{1}{|c|}{ Tvrdnja } \\
\hline 1. & $\begin{array}{l}\text { Smatram da je lako komunicirati s ljudima iz različitih } \\
\text { kultura. }\end{array}$ \\
\hline 2. & $\begin{array}{l}\text { U interakciji s ljudima iz različitih kultura bojim se izraža- } \\
\text { vati / progovoriti. }\end{array}$ \\
\hline 3. & Dobro se slažem s ljudima iz različitih kultura. \\
\hline
\end{tabular}




\begin{tabular}{|c|c|}
\hline 4. & $\begin{array}{l}\text { Nisam uvijek osoba kakvom se činim kad komuniciram s } \\
\text { ljudima iz različitih kultura. }\end{array}$ \\
\hline 5. & $\begin{array}{l}\text { Sposobna/-an sam jasno izraziti svoje ideje u interakciji s } \\
\text { ljudima iz različitih kultura. }\end{array}$ \\
\hline 6. & $\begin{array}{l}\text { Imam poteškoća s gramatikom u interakciji s ljudima iz } \\
\text { različitih kultura. }\end{array}$ \\
\hline 7. & $\begin{array}{l}\text { Mogu uspješno odgovarati na pitanja u interakciji s ljudima } \\
\text { iz različitih kultura. }\end{array}$ \\
\hline 8. & Teško je osjećati da su mi osobe iz različitih kultura slične. \\
\hline 9. & $\begin{array}{l}\text { Koristim prikladan kontakt očima kada komuniciram s } \\
\text { ljudima iz različitih kultura. }\end{array}$ \\
\hline 10. & $\begin{array}{l}\text { Imam problema s razlikovanjem poruka koje samo } \\
\text { informiraju i poruka kojima me se uvjerava u nešto } \\
\text { (eng. informative and persuasive messages) u interakciji s } \\
\text { ljudima iz različitih kultura. }\end{array}$ \\
\hline 11. & $\begin{array}{l}\text { Uvijek znam započeti razgovor u interakciji s ljudima iz } \\
\text { različitih kultura. }\end{array}$ \\
\hline 12. & $\begin{array}{l}\text { Često mi promakne što se događa tijekom interakcije s } \\
\text { ljudima iz različitih kultura. }\end{array}$ \\
\hline 13. & $\begin{array}{l}\text { Osjećam se opušteno u interakciji s ljudima iz različitih } \\
\text { kultura. }\end{array}$ \\
\hline 14. & $\begin{array}{l}\text { Često se ponašam kao potpuno drugačija osoba u interakciji } \\
\text { s ljudima iz različitih kultura. }\end{array}$ \\
\hline 15. & $\begin{array}{l}\text { Uvijek pokazujem poštivanje prema osobama iz različitih } \\
\text { kultura tijekom naše interakcije. }\end{array}$ \\
\hline 16. & $\begin{array}{l}\text { Uvijek osjećam da postoji distanca tijekom interakcije s } \\
\text { osobama iz različitih kultura. }\end{array}$ \\
\hline 17. & $\begin{array}{l}\text { Smatram da imam puno toga zajedničkog s osobama iz } \\
\text { različitih kultura tijekom naše interakcije. }\end{array}$ \\
\hline 18. & $\begin{array}{l}\text { Smatram da je najbolji način da se ponašam tako da budem } \\
\text { svoj/-a kada komuniciram s ljudima iz različitih kultura. }\end{array}$ \\
\hline 19. & $\begin{array}{l}\text { Smatram da se tijekom naše interakcije lako poistovjetiti s } \\
\text { osobama iz različitih kultura. }\end{array}$ \\
\hline
\end{tabular}




\begin{tabular}{|l|l|}
\multicolumn{1}{|c|}{20.} & $\begin{array}{l}\text { Uvijek pokazujem poštivanje prema mišljenjima osoba iz } \\
\text { različitih kultura tijekom naše interakcije. }\end{array}$ \\
\hline Cronbach $\alpha$ & 0.85 \\
\hline $\mathrm{M}(\mathrm{sd})$ & $72.94(9.73)$ \\
\hline raspon & $45-94$ \\
\hline $\begin{array}{l}\text { prosječna } \mathrm{r} \\
\text { među } \\
\text { česticama }\end{array}$ & 0.21 \\
\hline K-S d & $0.07, \mathrm{p}>0.05$ \\
\hline
\end{tabular}

Treći dio je Upitnik za ispitivanje glazbenih preferencija. Zadatak sudionika bio je da, nakon odslušanog glazbenog ulomka, na ljestvici Likertova tipa zaokruživanjem brojeva od jedan do pet (1=uopće mi se ne sviđa; 5=jako mi se sviđa) procijene stupanj estetskog doživljaja pojedinog glazbenog ulomka te da označe je li im glazbeni ulomak poznat od ranije.

U istraživanju je korišten glazbeni nosač zvuka na kojemu se nalazi deset glazbenih ulomaka dječjih glazbi svijeta (Hartmut E. Höfele i Freunde, Jibuli Kinderlieder Spiele und Tänze aus aller Welt) svaki u trajanju od oko jedne minute. Glazbeni nosač zvuka konstruiran je isključivo za potrebe ovog istraživanja, a kriterij izbora glazbenih ulomaka bili su postavljeni istraživački problemi. Psihometrijske značajke upitnika prikazane su u Tablici 3.

Tablica 3. Psihometrijske značajke Upitnika za ispitivanje glazbenih preferencija

\begin{tabular}{|l|l|}
\hline \multicolumn{1}{|c|}{$\begin{array}{c}\text { Broj } \\
\text { ulomka }\end{array}$} & \multicolumn{1}{c|}{ Glazbeni ulomak } \\
\hline 1. & Funga a la feeya (Gana) \\
\hline 2. & Arirang (Koreja) \\
\hline 3. & Ajde Jano (Srbija) \\
\hline 4. & Jibuli, jibuli (Tanzanija) \\
\hline 5. & Lelola (Španjolska i Južna Amerika) \\
\hline 6. & Oteng' teng' (Kenija) \\
\hline 7. & Mwana wange (Uganda) \\
\hline
\end{tabular}




\begin{tabular}{|l|l|}
\hline 8. & Berjasonka (Rusija) \\
\hline 9. & A, a, a bak geldi kis baba (Turska i Njemačka) \\
\hline 10. & Aka Tombo (Japan) \\
\hline Cronbach $\alpha$ & 0.86 \\
\hline M (sd) & $33.62(7.02)$ \\
\hline raspon & $10-50$ \\
\hline $\begin{array}{l}\text { prosječna } \mathrm{r} \\
\text { među } \\
\text { česticama }\end{array}$ & 0.38 \\
\hline K-S d & $0.08, \mathrm{p}>0.05$ \\
\hline
\end{tabular}

U Tablici 4 prikazan je prosječni stupanj preferencija glazbenih ulomaka. Sudionici su najvišim ocjenama ocijenili pjesmu Lelola (Španjolska i Južna Amerika), a najnižim pjesmu Mwana wange (Uganda).

Tablica 4. Prosječni stupanj preferencija glazbenih primjera

\begin{tabular}{|l|c|c|c|c|}
\hline Glazbeni primjer & M & min. & max. & SD \\
\hline Funga a la feeya (Gana) & 3,79 & 1,00 & 5,00 & 1,05 \\
\hline Arirang (Koreja) & 3,25 & 1,00 & 5,00 & 1,05 \\
\hline Ajde Jano (Srbija) & 3,49 & 1,00 & 5,00 & 1,13 \\
\hline Jibuli, jibuli (Tanzanija) & 3,23 & 1,00 & 5,00 & 1,00 \\
\hline $\begin{array}{l}\text { Lelola (Španjolska i Južna } \\
\text { Amerika) }\end{array}$ & 4,13 & 1,00 & 5,00 & 1,00 \\
\hline Oteng' teng' (Kenija) & 3,14 & 1,00 & 5,00 & 1,05 \\
\hline Mwana wange (Uganda) & 2,76 & 1,00 & 5,00 & 1,01 \\
\hline Berjasonka (Rusija) & 3,56 & 1,00 & 5,00 & 1,04 \\
\hline $\begin{array}{l}\text { A, a, a bak geldi kis baba } \\
\text { (Turska i Njemačka) }\end{array}$ & 3,22 & 1,00 & 5,00 & 1,17 \\
\hline Aka Tombo (Japan) & 3,04 & 1,00 & 5,00 & 1,11 \\
\hline
\end{tabular}




\section{Rezultati i diskusija}

H1 Studenti koji su završili gimnaziju i studenti viših godina studija, u odnosu na studente iz strukovnih škola i studente nižih godina studija, imaju višu razinu interkulturalne efikasnosti. Kako bi se istražilo razlikuje li se razina interkulturalne efikasnosti studenata s obzirom na vrstu završenog srednjoškolskog obrazovanja i dob/godinu studija, provedena je dvosmjerna analiza varijance. Rezultati pokazuju da nema razlike $\mathrm{u}$ razini interkulturalne efikasnosti studenata s obzirom na vrstu završene srednje škole ni s obzirom na njihovu dob/godinu studija. Nije utvrđen niti značajan interakcijski učinak završene srednje škole i dobi/ godine studija na razinu interkulturalne efikasnosti (Tablica 5), čime je odbačena postavljena hipoteza.

Dobiveni rezultati razlikuju se od rezultata istraživanja Petrović i Zlatković (2009) koje su istražile razinu interkulturalne osjetljivosti studenata učiteljskog studija, odnosno varijable koje bi mogle biti prediktori interkulturalne osjetljivosti. Rezultati potvrđuju da studenti viših godina studija, u odnosu na mlađe studente, pokazuju višu razinu interkulturalne osjetljivosti (Petrović i Zlatković, 2009). Nadalje, Neto (2006) navodi značajnu ulogu obrazovanja na oblikovanje interkulturalne osjetljivosti studenata. Do sličnih rezultata dolazi i Probst (2003) koji smatra da je povećanje interkulturalne tolerancije i prevladavanje rodnih stereotipa upravo rezultat kvalitetnije i intenzivnije interkulturalne poduke učenika i studenata.

Tablica 5. Razlike u razini interkulturalne efikasnosti s obzirom na vrstu završene srednje škole i dob/godinu studija

\begin{tabular}{|c|c|c|c|c|c|c|}
\hline \multicolumn{2}{|c|}{$\begin{array}{c}\text { Interkulturalna } \\
\text { efikasnost }\end{array}$} & M & $\mathbf{N}$ & $\mathbf{F}$ & df & $\mathbf{p}$ \\
\hline \multirow{2}{*}{ Srednja škola } & strukovna & 3.64 & 51 & \multirow{2}{*}{0.01} & \multirow{2}{*}{1.137} & \multirow{2}{*}{0.95} \\
\hline & gimnazija & 3.63 & 90 & & & \\
\hline \multirow{2}{*}{ Godina studija } & mlađi & 3.60 & 54 & \multirow{2}{*}{0.652} & \multirow{2}{*}{1.137} & \multirow{2}{*}{0.42} \\
\hline & stariji & 3.67 & 87 & & & \\
\hline
\end{tabular}




\begin{tabular}{|c|c|c|c|c|c|c|}
\hline \multirow{4}{*}{$\begin{array}{l}\text { Interakci- } \\
\text { ja srednja } \\
\text { škola* godina } \\
\text { studija }\end{array}$} & $\begin{array}{l}\text { strukov- } \\
\text { na, mlađi }\end{array}$ & 3.63 & 23 & \multirow{4}{*}{0.477} & \multirow{4}{*}{1.137} & \multirow{4}{*}{0.49} \\
\hline & $\begin{array}{l}\text { strukov- } \\
\text { na, stariji }\end{array}$ & 3.64 & 28 & & & \\
\hline & $\begin{array}{l}\text { gimnazi- } \\
\text { ja, mlađi }\end{array}$ & 3.57 & 31 & & & \\
\hline & $\begin{array}{l}\text { gimnazi- } \\
\text { ja, stariji }\end{array}$ & 3.70 & 59 & & & \\
\hline
\end{tabular}

H2: Studenti koji su završili gimnaziju i studenti viših godina studija, u odnosu na studente iz strukovnih škola i studente nižih godina studija, pokazuju veće preferencije glazbi svijeta. U svrhu ispitivanja razlike studentskih preferencija glazbi svijeta s obzirom na vrstu završenog srednjoškolskog obrazovanja i dob/godinu studija ponovno je provedena dvosmjerna analiza varijance. Kao i u slučaju razine interkulturalne efikasnosti, i ovdje je potvrđeno nepostojanje razlike s obzirom na vrstu završene srednje škole i dob/godinu studija. Nije utvrđen ni značajan interakcijski učinak završene srednje škole i dobi/godine studija na preferencije glazbi svijeta (Tablica 6). Time je odbačena postavljena hipoteza.

Dobiveni rezultati nisu u skladu s rezultatima istraživanja koji potvrđuju utjecaj srednjoškolske poduke i dobi/godine studija na glazbene preferencije učenika i studenata (Howard, 2018; Kim i Yoon, 2016). Iako smo pretpostavili da bi gimnazijska glazbena poduka i glazbena poduka tijekom visokoškolskog obrazovanja mogle utjecati na formiranje glazbenih preferencija sudionika, to nije bio slučaj.

Tablica 6. Razlike u preferencijama glazbi svijeta s obzirom na vrstu završene srednje škole i dob/godinu studija

\begin{tabular}{|l|l|l|l|l|l|l|}
\hline \multicolumn{2}{|c|}{ Preferencije glazbi svijeta } & M & N & F & df & p \\
\hline \multirow{2}{*}{ Srednja škola } & strukovna & 3.46 & 51 & \multirow{2}{*}{2.66} & 1.137 & 0.11 \\
\cline { 2 - 7 } & gimnazija & 3.26 & 90 & & & \\
\hline
\end{tabular}




\begin{tabular}{|c|c|c|c|c|c|c|}
\hline \multirow{2}{*}{ Godina studija } & mlađi & 3.28 & 54 & \multirow{2}{*}{1.77} & \multirow{2}{*}{1.137} & \multirow{2}{*}{0.19} \\
\hline & stariji & 3.44 & 87 & & & \\
\hline \multirow{4}{*}{$\begin{array}{l}\text { Interakcija } \\
\text { srednja } \\
\text { škola*godina } \\
\text { studija }\end{array}$} & $\begin{array}{l}\text { strukovna, } \\
\text { mlađi }\end{array}$ & 3.44 & 23 & \multirow{4}{*}{0.92} & \multirow{4}{*}{1.137} & \multirow{4}{*}{0.32} \\
\hline & $\begin{array}{l}\text { strukovna, } \\
\text { stariji }\end{array}$ & 3.49 & 28 & & & \\
\hline & $\begin{array}{l}\text { gimnazija, } \\
\text { mlađi }\end{array}$ & 3.12 & 31 & & & \\
\hline & $\begin{array}{l}\text { gimnazija, } \\
\text { stariji }\end{array}$ & 3.40 & 59 & & & \\
\hline
\end{tabular}

H3: Studenti koji imaju višu razinu interkulturalne efikasnosti, pokazuju i veće preferencije glazbi svijeta. Kako bismo ispitali kakav je odnos između interkulturalne efikasnosti i preferencija glazbi svijeta, izračunate su korelacije između navedenih varijabli (Tablica 7). Rezultati potvrđuju da sudionici koji imaju višu razinu interkulturalne efikasnosti pokazuju i veće preferencije glazbi svijeta, čime je potvrđena treća hipoteza.

Rezultati brojnih istraživanja govore u prilog povezanosti interkulturalne osjetljivosti i interkulturalnih stavova s jedne, te preferencija glazbi svijeta, s druge strane (Dobrota, 2016; Fung, 1994).

Tablica 7. Povezanost između razine interkulturalne efikasnosti i preferencija glazbi svijeta

\begin{tabular}{|c|c|c|c|c|}
\hline Varijable & M & SD & $\begin{array}{c}\text { Interkultural- } \\
\text { na efikasnost }\end{array}$ & $\begin{array}{c}\text { Preferencije } \\
\text { glazbi svijeta }\end{array}$ \\
\hline Interkulturalna efikasnost & 3.65 & 0.49 & 1.00 & $0.32^{*}$ \\
\hline Preferencije glazbi svijeta & 3.36 & 0.70 & $0.32^{*}$ & 1.00 \\
\hline
\end{tabular}

H4: Studenti pokazuju veće preferencije poznatih u odnosu na nepoznate glazbene ulomke. Pokušavajući utvrditi utječe li poznavanje glazbenih ulomaka na studentske preferencije, izračunate su korelacije između poznatosti i glazbenih preferencija (Tablica 8). Uočeno je postojanje takvih korelacija za četiri glazbena primjera, čime je djelomično prihvaćena posljednja hipoteza. 
Rezultati brojnih istraživanja potvrđuju da je poznavanje glazbe značajan prediktor glazbenih preferencija (Dobrota i Reić Ercegovac, 2017; Tan et al., 2012; Teo et al., 2008). Naime, boljim upoznavanjem glazbenoga djela i njegovih glazbeno-izražajnih sastavnica, povećavaju se i preferencije takve glazbe.

Tablica 8. Povezanost između poznatosti i preferencija glazbenih ulomaka

\begin{tabular}{|l|c|c|c|}
\hline \multicolumn{1}{|c|}{ Glazbeni ulomci } & $\begin{array}{c}\text { Nepoznato } \\
\text { (f) }\end{array}$ & $\begin{array}{c}\text { Poznato } \\
\text { (f) }\end{array}$ & $\begin{array}{c}\text { Korelacija } \\
\text { između sviđa- } \\
\text { nja i poznatosti }\end{array}$ \\
\hline Funga a la feeya (Gana) & 134 & 7 & 0.14 \\
\hline Arirang (Koreja) & 124 & 17 & $0.26^{*}$ \\
\hline Ajde Jano (Srbija) & 124 & 17 & $0.26^{*}$ \\
\hline Jibuli, jibuli (Tanzanija) & 138 & 3 & 0.06 \\
\hline $\begin{array}{l}\text { Lelola (Španjolska i } \\
\text { Južna Amerika) }\end{array}$ & 125 & 16 & $0.20^{*}$ \\
\hline Oteng' teng' (Kenija) & 138 & 3 & 0.07 \\
\hline Mwana wange (Uganda) & 139 & 2 & -0.03 \\
\hline Berjasonka (Rusija) & 136 & 5 & 0.15 \\
\hline $\begin{array}{l}\text { A, a, a bak geldi kis baba } \\
\text { (Turska i Njemačka) }\end{array}$ & 134 & 7 & $0.18^{*}$ \\
\hline Aka Tombo (Japan) & 139 & 2 & 0.10 \\
\hline
\end{tabular}

\section{Zaključak}

Rezultatima ovoga istraživanja nije potvrđen utjecaj vrste završene srednje škole i dobi/godine studija na razinu interkulturalne efikasnosti studenata niti na njihove preferencije glazbi svijeta. Potvrđeno je postojanje povezanosti između razine interkulturalne efikasnosti i preferencija glazbi svijeta te između poznavanje glazbe i preferencija glazbenih ulomaka.

Dio rezultata koji se odnosi na nepostojanje utjecaja obrazovanja na razinu interkulturalne efikasnosti i na preferencije glazbi svijeta mo- 
guće je objasniti nedovoljnim interkulturalnim interakcijama učenika i studenata u hrvatskim školama i na fakultetima. Za pretpostaviti je da oni takve interakcije uglavnom doživljavaju kao teorijski konstrukt. Rezultati koji potvrđuju povezanost između razine interkulturalne efikasnosti i preferencija glazbi svijeta te između poznavanja glazbe i preferencija glazbenih ulomaka uglavnom su u skladu s rezultatima ranije provedenih istraživanja.

Dobiveni rezultati imaju značajne glazbeno-pedagoške implikacije. Obrazovni sustav, na svim svojim razinama, trebao bi osiguravati mogućnosti za razvoj interkulturalne svijesti, interkulturalne osjetljivosti i interkulturalne efikasnosti (Salo-Lee, 2006). Kako ističu Bećirović, Brdarević Čeljo i Zavrl (2019), to je posebno važno na visokoškolskoj razini obrazovanja i to zbog uspostavljanja društvene harmonije, bolje suradnje s različitim pojedincima, ali i zbog veće mobilnosti studenata i nastavnika. Navedeni autori naglašavaju i važnost internacionalizacije u provođenju različitih vrsta istraživanja, što je u potpunosti u skladu s postavkama suvremenog odgojno-obrazovnog procesa na svim razinama obrazovanja u uvjetima heterogenih društvenih sredina.

Glazba predstavlja moćno sredstvo razvijanja interkulturalnih kompetencija. Stoga bi glazbeni pedagozi trebali osuvremeniti svoj glazbeno-pedagoški rad i koncipirati nastavu glazbe prema načelima interkulturalnog glazbenog obrazovanja, upoznajući pritom različite glazbe svijeta i kulture iz kojih one potječu. To se odnosi i na oblikovanje glazbenih kolegija na visokoškolskoj razini, prije svega na muzičkim akademijama i učiteljskim fakultetima. U tom smislu potrebno je prevladati konzervativizam koji je često prisutan na visokoškolskim institucijama i staviti u prvi plan interakciju i komunikaciju, prevladavajući na taj način restriktivnu perspektivu i pomicati se prema kulturnoj raznolikosti i holističkom pristupu obrazovanju. 


\section{Literatura}

Bećirović, Senad; Brdarević Čeljo, Amna i Zavrl, Irena (2019), »Research into intercultural effectiveness in a multicultural educational milieu in Bosnia and Herzegovina«, Economic research - Ekonomska istraživanja, 32(1), str. 1336-1361. https://doi.org/10.1080/1331677X.2019.1629329

Bray, David (2000), »An examination of GCSE music uptake rates«, British Journal of Music Education, 17(1), str. 79-89. https://doi.org/10.1017/ S0265051700000176

Campbell, Patricia S. (2003), »Ethnomusicology and music education: Crossroads for knowing music, education, and culture«, Research Studies in Music Education, 21(1), str. 16-30. https://doi.org/10.1177/1321103X030210010201

Chen, Guo-Ming i Starosta, William J. (1996), »Intercultural communication competence: A synthesis«, Annals of the International Communication Association, 19(1), str. 353-384. https://doi.org/10.1080/23808985.1996.11678935

Chen, Guo-Ming i Starosta, William J. (1997), »A review of the concept of intercultural sensitivity«, Human Communication, 1, str. 1-16.

Cushner, Kenneth i Brislin, Richard W. (1996), Intercultural interactions: A practical guide, Beverly Hills, CA: Sage.

Dobrota, Snježana (2012), Uvod u suvremenu glazbenu pedagogiju, Split: Filozofski fakultet Sveučilišta u Splitu.

Dobrota, Snježana (2016), »Povezanost između interkulturalnih stavova studenata i preferencija glazbi svijeta«, Život i škola: časopis za teoriju i praksu odgoja i obrazovanja, 62(1), str. 209-218.

Dobrota, Snježana i Reić Ercegovac, Ina (2017), »Music preferences with regard to music education, informal influences and familiarity of music amongst young people in Croatia«, British Journal of Music Education, 34(1), str. 41-55. https://doi.org/10.1017/S0265051716000358

Fung, Victor C. (1994), »Undergraduate nonmusic majors' world music preference and multicultural attitudes«, Journal of Research in Music Education, 42(1), str. 4557. https://doi.org/10.2307/3345336

Fylkesnes, Sandra (2018), »Whiteness in teacher education research discourses: A review of the use and meaning making of the term cultural diversity «, Teaching and Teacher Education, 71, str. 24-33. https://doi.org/10.1016/j. tate.2017.12.005

Hammer, Mitchell R.; Gudykunst, William B. i Wiseman, Richard L. (1978), "Dimensions of intercultural effectiveness: An exploratory study«, International Journal of Intercultural Relations, 2(4), str. 382-393. https://doi. org/10.1016/0147-1767(78)90036-6

Howard, Karen (2018), »The emergence of children's multicultural sensitivity: An elementary school music culture project«, Journal of Research in Music Education, 66(3), str. 261-277. https://doi.org/10.1177/0022429418784594

Hutchins, Darvelle i Goldstein-Hode, Marlo (2019), »Exploring faculty and staff development of cultural competence through communicative learning in an 
online diversity course«, Journal of Diversity in Higher Education, advance online publication. https://doi.org/10.1037/dhe0000162

Kang, Sangmi (2016), »The history of multicultural music education and its prospects: The controversy of music universalism and its application«, Update: Applications of Research in Music Education, 34(2), str. 21-28. https://doi. org/10.1177/8755123314548044

Kim, Misook i Yoon, Moonjung (2016), »Research on the multicultural music education at the college level«, International Journal of Humanities and Social Sciences, 5(9), str. 290-299.

Kim, So Jung; Wee, Su-Jeong i Lee, Young Mi (2016), »Teaching kindergartners racial diversity through multicultural literature: A case study in a kindergarten classroom in Korea«, Early Education and Development, 27(3), str. 402420. https://doi.org/10.1080/10409289.2015.1069110

King, Patricia M.; Perez, Rosemary J. i Shim, Woo-jeong (2013), »How college students experience intercultural learning: Key features and approaches«, Journal of Diversity in Higher Education, 6(2), str. 69-83. https://doi. org/10.1037/a0033243

Klopper, Christopher (2010), »Intercultural musicianship: A collective and participatory form of music exchange across the globe «, Australian Journal of Music Education, 1, str. 48-57.

Neto, Félix (2006), »Changing intercultural attitudes over time«, Journal of Intercultural Communication, 12, str. 4.

Petrović, Danijela S. i Zlatković, Blagica (2009), »Intercultural sensitivity of future primary school teachers«, u: Popov, N., Wolhuter, C., Leutwyler, B., Mihova, M., Ogunleye, J., \& Bekiroğullari, Z. (ur.), Comparative Education, Teacher Training, Education Policy, Social Inclusion and Child Psychology, Sofia: Bureau for Educational Services, 7, str. 121-128.

Portalla, Tamra i Chen, Guo-Ming (2010), » The development and validation of the intercultural effectiveness scale«, Intercultural Communication Studies, 19(3), str. 21-37.

Probst, Tahira M. (2003), »Changing attitudes over time: assessing the effectiveness of a workplace diversity course «, Teaching of Psychology, 30(3), str. 236-239. https://doi.org/10.1207/S15328023TOP3003_09

Rojko, Pavel (2001), »Povijest glazbe/glazbena umjetnost u glazbenoj školi i gimnaziji«, Tonovi: časopis glazbenih i plesnih pedagoga, 16(1, 2), str. 3-19.

Ross, Malcolm (1995), »What's wrong with school music? A response to Malcolm Ross«, British Journal of Music Education, 12(3), str. 185-201. https://doi. org/10.1017/S0265051700002692

Salo-Lee, Liisa (2006), »Intercultural competence in research and practice. Challenges of globalization for intercultural leadership and team work «, u: Aalto, Nancy i Reuter, Ewald (ur.), Aspects of Intercultural Dialogue. Theory, Research, Teaching, Köln: Saxa-Verlag, str. 79-92. 
Tan, Xueli; Yowler, Charles J.; Super, Dennis M., i Fratianne, Richard B. (2012), »The interplay of preference, familiarity, and psychophysical properties in defining relaxation music«, Journal of Music Therapy, 49(2), str. 150-179. https://doi.org/10.1093/jmt/49.2.150

Teo, Timothy; Hargreves, David J. i Lee, June (2008), »Musical preference, identification, and familiarity: A multicultural comparison of secondary students from Singapore and the United Kingdom «, Journal of Research in Music Education, 56(1), str. 18-32. https://doi.org/10.1177/0022429408322953

\section{INTERCULTURAL EFFECTIVENESS AND WORLD MUSIC PREFERENCES IN THE CONTEXT OF HIGHER EDUCATION}

\section{Snježana Dobrota, Mirna Vukić}

The paper explored the influence of high school education and age/year of study on students' intercultural effectiveness and their world music preferences, the relationship between intercultural effectiveness and world music preferences, and the influence of familiarity of music on music preferences. The research was conducted on a sample of students from different faculties of the University of Split and the University of Zagreb, using a questionnaire composed of three parts: The Sociodemographic Questionnaire, The Intercultural Effectiveness Scale and The Music preferences Questionnaire. The results do not confirm the influence of the type of high school education or agelyear of study on the level of the students' intercultural effectiveness, nor on their world music preferences. The existence of a relationship between the level of students' intercultural effectiveness, world music preferences and between familiarity of music and music preferences has been confirmed. The obtained results have significant implications for music pedagogy, especially in the context of higher education.

Keywords: music pedagogy, intercultural effectiveness, preferences of world music, higher education 